\title{
An experimental study on characteristics of post-CHF heat transfer in the high subcritical pressure region near to the critical pressure
}

\author{
Takashi MAWATARI* and Hideo MORI** \\ * Department of Mechanical Engineering, Graduate School of Engineering, Kyushu University \\ 744, Motooka, Nishi-ku, Fukuoka 819-0395, Japan \\ E-mail: mawatari@therme.mech.kyushu-u.ac.jp \\ ${ }^{* *}$ Department of Mechanical Engineering, Kyushu University \\ 744, Motooka, Nishi-ku, Fukuoka 819-0395, Japan
}

Received 18 November 2015

\begin{abstract}
Supercritical pressurized water cooled reactor (SCWR), which has a once-through water cooled reactor for supplying supercritical pressure steam at high temperature to a turbine system, is one of the next generation reactors for the purpose of improving economic efficiency and safety. In the SCWR system, water pressure passes through the critical pressure during startup, shutdown and in case of loss of coolant accident (LOCA). Similarly, in fossil-fired power plants, once-through boilers of sliding pressure type operate at supercritical pressure during nominal load, but they work near the critical pressure during partial load. In the high subcritical pressure region slightly below the critical pressure, critical heat flux (CHF) phenomenon readily occurs at relatively low heat flux and in a high subcooled region, and then it causes serious damages to fuel rods or boiler tubes due to the abrupt temperature rise in the rod or tube. In this study, experiments on post-CHF heat transfer in such the high subcritical pressure region near the critical pressure (reduced pressure range of 0.924 up to 0.992$)$ in the range of mass flux $400-1000 \mathrm{~kg} /\left(\mathrm{m}^{2} \cdot \mathrm{s}\right)$ with a circular tube of $4.4 \mathrm{~mm}$ ID in vertical upward flow. HCFC22 and HFC134a were used as the test fluids. Based on the obtained data, characteristics of the post-CHF heat transfer were examined and found to be classified into two distinctive types mainly according to flow rate conditions. The influences of pressure, flow rate and heat flux on the characteristics were also clarified.
\end{abstract}

Key words : Heat transfer, Post-CHF, Film boiling, Near-critical pressure

\section{Introduction}

Supercritical pressurized water cooled reactor (SCWR) is one of the next generation reactors for the purpose of improving economic efficiency and safety (Oka and Koshizuka, 2001). It has a once-through water cooled reactor for supplying supercritical pressure steam at high temperature to a turbine system. Water pressure in the SCWR system passes through the critical pressure during startup, shutdown and in case of loss of coolant accident (LOCA). Similarly, in fossil-fired power plants, sliding-pressure type once-through boilers operate at supercritical pressure during nominal load, but they are set going near the critical pressure for partial load. According to the report by Bähr et al. (1969), in the high subcritical pressure region which is slightly below the critical pressure, namely in the near-critical pressure region of the reduced pressure over around 0.95 , critical heat flux (CHF) phenomenon easily occurs at relatively low heat flux. What is worse, the CHF phenomenon is likely to be caused by film boiling in high subcooled liquid region, and also the minimum heat transfer coefficient becomes very small. Consequently, fuel rods or boiler tubes may be damaged severely due to the abrupt temperature rise in the rod or tube. Therefore, it is important to clarify the characteristics of $\mathrm{CHF}$ at which the $\mathrm{CHF}$ phenomenon occurs and heat transfer in the region downstream of the $\mathrm{CHF}$ occurring location, that is, the post-CHF heat transfer, and especially those in near-critical pressure region must be 
figured out.

On CHF, many investigations were made for upward flow (Tong and Tang, 1997), but there were limited a few studies for the near-critical pressure condition. Vijayarangan et al. (2006) performed experiments of CHF in tube flow of HFC134a in the reduced pressure range from 0.24 up to 0.99. Chun et al. (2007) obtained CHF data of HFC134a at the reduced pressure of 0.74 up to 0.99 in a $5 \times 5$ square-arrayed heater rod bundle channel. They reported that the CHF value sharply decreased in the near-critical pressure region as the pressure approached to the critical pressure. Mawatari et al. (2012) conducted experiments on CHF in a high subcooled liquid region at the near-critical pressure of the reduced pressure over 0.962 up to 0.992 . They reported that the CHF characteristics at the near-critical pressure were different from those at lower pressure, and found out that the characteristics were classified into four distinctive regimes according to the quality at the occurring location of the CHF phenomenon.

For prediction of CHF at high subcritical pressures, a look-up table was developed by Groeneveld et al. (2007) and a correlation was proposed by Mori et al. (1999). However, their application was limited below the reduced pressures 0.95 and 0.96 , respectively, and they mainly focused on CHF occurrence in the saturated or low subcooled region. Hence, their prediction is not sufficient for CHF in a high subcooled liquid region at the near-critical pressure of the reduced pressure over 0.95. Based on the experimental CHF results and data by Mawatari et al. (2012), Kariya et al. (2013) developed a new dimensionless correlation to predict CHF at the near-critical pressure.

As for CHF at the near-critical pressure, the characteristics are being clarified and the prediction correlation is being developed.

On post-CHF heat transfer at high subcritical pressures, some studies have been made, though most of them were limited to post-dryout heat transfer which corresponds to the case when CHF phenomenon occurs in the saturated or low subcooled liquid region. Herkenrath et al. (1967) and Becker et al. (1983) performed experiments with water in the reduced pressure range of 0.64 up to 1.13 including supercritical pressure conditions and 0.14 to 0.93 , respectively. Also, Bishop et al. (1965) conducted experiments of water in the reduced pressure range from 0.76 to 0.97 , and proposed an empirical correlation for the post-CHF heat transfer coefficient as shown in Eq. (1).

$$
\left(\frac{\alpha D}{\lambda_{f}}\right)=0.0193\left(\frac{G D}{\mu_{f}}\right)^{0.8}\left(\frac{\mu_{f} c_{p f}}{\lambda_{f}}\right)^{1.23}\left(\frac{\rho_{v}}{\rho_{b}}\right)^{0.68}\left(\frac{\rho_{v}}{\rho_{l}}\right)^{0.068}
$$

where $\alpha$ is the heat transfer coefficient, $D$ is the tube inside diameter, $G$ is the mass flux, and $\lambda, \mu, c_{p}$ and $\rho$ are the fluid thermal conductivity, viscosity, isobaric specific heat and density, respectively. The subscript $f$ refers to the film temperature which is the average of wall temperature and saturation temperature, and the bulk fluid density $\rho_{b}$ is calculated by Eq. (2) with the saturated liquid density $\rho_{l}$ and the saturated vapor density $\rho_{v}$.

$$
\rho_{b}=\frac{1}{\frac{1-x}{\rho_{l}}+\frac{x}{\rho_{v}}}
$$

where $x$ is the thermal equilibrium quality. The Bishop et al. correlation, Eq. (1), can predict the heat transfer coefficient of stable film boiling of water in the saturated region for the wide pressure range from 3.95 to $21.7 \mathrm{MPa}$ (the reduced pressure 0.179 to 0.984 ).

Hammouda et al. (1996) and Nakla et al. (2011) examined characteristics of post-CHF heat transfer based on their experimental data of HFC134a, although the reduced pressure range of their data was not high, but limited to low below 0.39 and 0.59 , respectively. They reported four characteristic heat transfer regions, named Regions I, II, III and IV, corresponding to the differences in flow pattern. Regions I and II corresponded to the post-CHF heat transfer in the subcooled liquid region. However, for post-CHF heat transfer at the near-critical pressure in which CHF mainly arises from film boiling in a high subcooled region, the characteristics were not clarified yet.

As described above, as for post-CHF heat transfer at the near-critical pressure, there were few data and the characteristics were hardly clarified, compared to the CHF characteristics.

In this study, experiments were carried out on post-CHF heat transfer in upward flow within a tube in the near-critical pressure range of the reduced pressure from 0.924 up to 0.992 , using HCFC22 and HFC134a as the test fluids. The post-CHF heat transfer obtained in the present experiments entirely attributed to subcooled film boiling. Based on the data, the characteristics of post-CHF heat transfer at the near-critical pressure were examined and clarified, including the effects of pressure, flow rate and heat flux conditions. 


\section{Nomenclature}

$\begin{array}{lll}c_{p} & \text { isobaric specific heat } & {[\mathrm{kJ} / \mathrm{kg} \cdot \mathrm{K}]} \\ B o & \text { boiling number }=q /\left(G \Delta h_{l v}\right) & {[-]} \\ D & \text { tube inside diameter } & {[\mathrm{m}]} \\ G & \text { mass flux } & {\left[\mathrm{kg} /\left(\mathrm{m}^{2} \cdot \mathrm{s}\right)\right]} \\ h & \text { specific enthalpy } & {[\mathrm{kJ} / \mathrm{kg}]} \\ \Delta h_{l v} & \text { latent heat of vaporization } & {[\mathrm{kJ} / \mathrm{kg}]} \\ P & \text { pressure } & {[\mathrm{MPa}]} \\ P_{c} & \text { critical pressure } & {[\mathrm{MPa}]} \\ P_{r c} & \text { reduced pressure }=P / P_{c} & {[-]} \\ q & \text { heat flux } & {\left[\mathrm{kW} / \mathrm{m}^{2}\right]} \\ T & \text { temperature } & {\left[{ }^{\circ} \mathrm{C}\right]} \\ T_{w} & \text { inner wall surface temperature } & {\left[{ }^{\circ} \mathrm{C}\right]} \\ x & \text { thermal equilibrium quality } & {[-]} \\ \alpha & \text { heat transfer coefficient } & {\left[\mathrm{kW} /\left(\mathrm{m}^{2} \cdot \mathrm{K}\right)\right]} \\ \alpha_{\text {min }} & \text { minimum heat transfer coefficient } & {\left[\mathrm{kW} /\left(\mathrm{m}^{2} \cdot \mathrm{K}\right)\right]} \\ \lambda & \text { thermal conductivity } & {[\mathrm{kW} /(\mathrm{m} \cdot \mathrm{K})]} \\ \mu & \text { viscosity } & {[\mathrm{Pa} \cdot \mathrm{s}]} \\ \rho & \text { density } & {\left[\mathrm{kg} / \mathrm{m}^{3}\right]}\end{array}$

\section{Subscripts}

$\begin{array}{ll}\text { b } & \text { bulk fluid } \\ \text { CHF } & \text { at CHF location } \\ \text { f } & \text { film temperature } \\ \text { in } & \text { at inlet of the test section } \\ \text { l } & \text { saturated liquid } \\ \text { v } & \text { saturated vapor }\end{array}$

\section{Experimental facility and methods}

\subsection{Experimental facility}

Schematic illustrations of the test loop and the circular test tube are shown in Figs. 1(a) and (b). HCFC22 and HFC134a were used as the test fluids to substitute for water, since easy handling due to their low critical pressures and temperatures (4.99 $\mathrm{MPa}$ and $96{ }^{\circ} \mathrm{C}$ of $\mathrm{HCFC} 22$, and $4.06 \mathrm{MPa}$ and $101{ }^{\circ} \mathrm{C}$ of HFC134a). Physical properties of the test fluids were calculated using REFPROP 9.0 of National Institute of Standards and Technology (NIST) (Lemmon et al., 2010).

The test loop was a forced circulation loop. The fluid was circulated by the pump through the preheater, test section and cooler, and then returned to the pump. The fluid flowed vertically upward in the test section. Pressure in the loop was controlled by the accumulator connected to the high pressure nitrogen gas supply, and measured with precision pressure gauges. Flow rate was controlled by the flow control valves, and measured with the Coriolis type mass flow meters. Measurement errors of pressure and mass flow rate were $\pm 0.01 \mathrm{MPa}$ and $\pm 1 \%$, respectively. The test fluid was heated up to the required bulk fluid temperature or enthalpy at the inlet of the test section by the electric-heating type preheater, and the inlet and outlet bulk fluid temperatures were measured with K-type (Chromel-Alumel) thermocouples at the inlet and outlet mixing chambers of the test section, respectively. In addition, bulk fluid temperature was measured upstream of the preheater. 


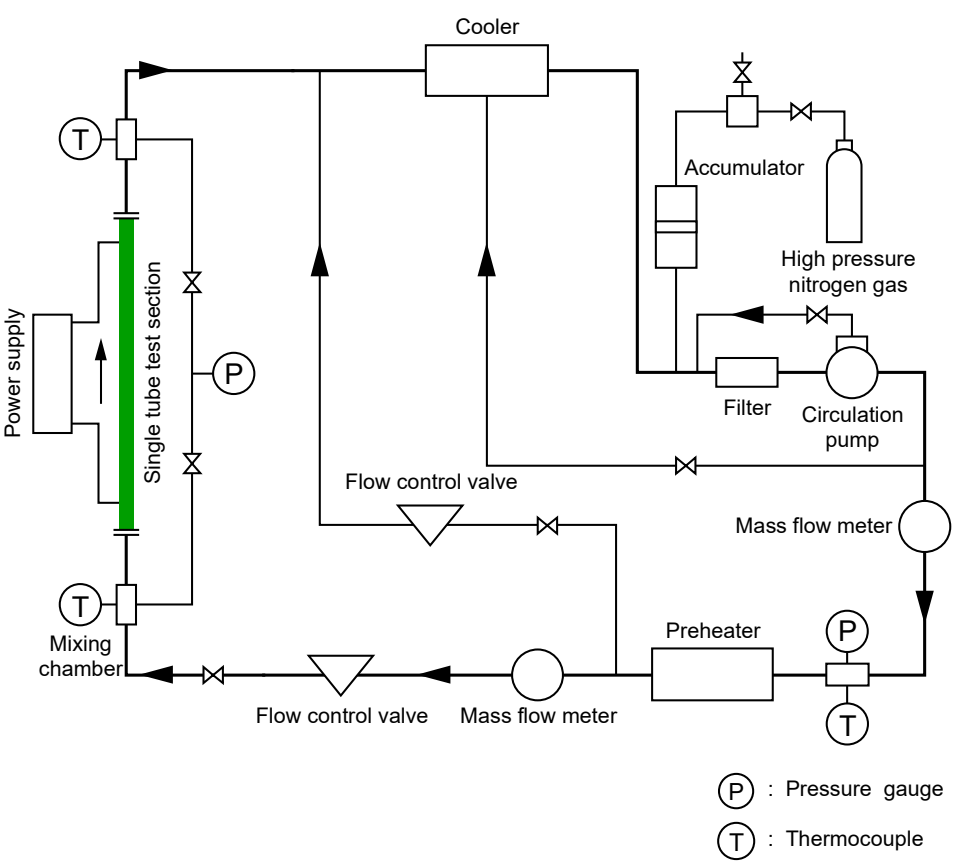

(a) Test loop

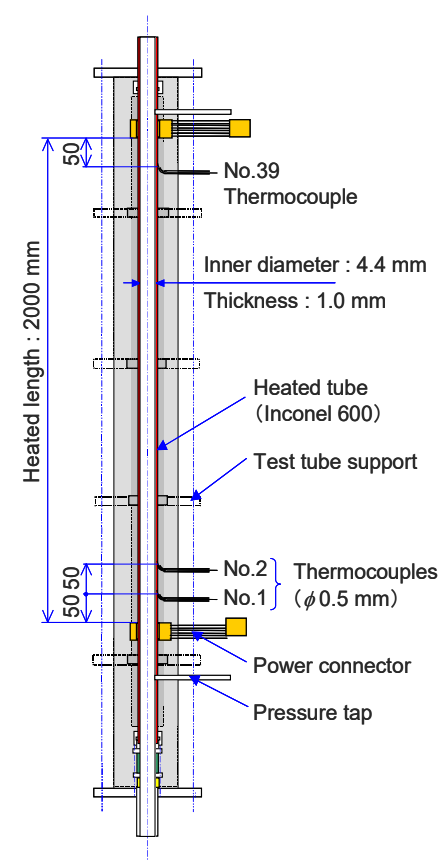

(b) Test tube

Fig. 1 Schematic illustrations of (a) test loop and (b) test tube.

The test section was a circular tube made of Inconel 600 as shown in Fig. 1(b) and vertically installed in the test loop. The tube had $4.4 \mathrm{~mm}$ ID, $6.4 \mathrm{~mm}$ OD and $2000 \mathrm{~mm}$ heating length, and it was uniformly heated by passing alternating current through the tube wall. Outer wall surface temperatures of the tube were measured with 39 K-type thermocouples welded on the outer wall surface at axially $50 \mathrm{~mm}$ intervals. At each cross-section, inner wall surface temperature was calculated from the measured outer wall surface temperature considering one-dimensional radial thermal conduction within the tube wall. The accuracy of temperature measurement was within $\pm 0.5{ }^{\circ} \mathrm{C}$. The experiments were made under the condition of the maximum wall temperature not exceeding approximately $150{ }^{\circ} \mathrm{C}$ to prevent decomposition of the test fluid.

\subsection{Experimental methods and conditions}

Experiments were carried out in the ranges of the reduced pressure of 0.962 to 0.992 for HCFC22 and 0.924 to 0.990 for HFC134a. The mass flux range was from 400 to $1000 \mathrm{~kg} /\left(\mathrm{m}^{2} \cdot \mathrm{s}\right)$. The experimental conditions are summarized in Table 1. The condition number means the number of combinations of pressure, flow rate and heat flux conditions.

The experiments were conducted by the following increasing heat flux method: heat flux was increased stepwise with keeping other conditions of pressure, flow rate and inlet fluid enthalpy at constant to cause CHF phenomenon somewhere in the tube at steady state. Heat transfer coefficient $\alpha$ was calculated by Eq. (3) using the heat flux $q$, the inner wall temperature $T_{w}$ and the bulk fluid temperature $T_{b}$ at each axial position of the tube.

$$
\alpha=\frac{q}{T_{w}-T_{b}}
$$

The heat flux was calculated from the electric input power and inner heated surface area of the test tube; and the bulk fluid temperature $T_{\mathrm{b}}$ was determined from the bulk fluid enthalpy evaluated from the heat balance between the inlet and each axial position of the tube.

High reproducibility of the experiments was confirmed, and it is shown in Fig. 2(a). The figure shows the distributions of measured inner wall temperature $T_{\mathrm{w}}$ and heat transfer coefficient $\alpha$ plotted against the thermal equilibrium quality $x$ with circle symbols in upper and lower diagrams, respectively. Solid line in the upper diagram denotes the bulk fluid temperature $T_{\mathrm{b}}$, and here the thermal equilibrium quality $x$ is extended to the subcooled liquid 
region where its value is negative. As seen in Fig. 2(a), the distributions of wall temperature and heat transfer coefficient coincided precisely for two data obtained on different dates.

To confirm less dependence of post-CHF heat transfer on the experimental method, two additional experiments were conducted using HFC134a: an increasing pressure method and an increasing flow rate method. In the increasing pressure method, fluid pressure was increased stepwise from the subcritical pressure of 3.90 MPa (the reduced pressure 0.96 ) to the supercritical pressure of $4.50 \mathrm{MPa}$ (the reduced pressure 1.11) with keeping other parameters constant, and in the increasing flow rate method, mass flux was raised step by step from 400 to $1000 \mathrm{~kg} /\left(\mathrm{m}^{2} \cdot \mathrm{s}\right)$ with holding other parameters constant. In both methods, post-CHF data were obtained at steady state. Figures 2(b) and (c) show the examples of comparison between the data obtained by the increasing heat flux method and the two above mentioned additional experimental methods. The difference was little in both of the CHF and post-CHF heat transfer.

\subsection{CHF location and post-CHF region}

In the present study, CHF location and post-CHF region in the flow direction were determined as illustrated in Figs. 3(a) and (b), which are examples of the present experimental results. These figures show the relation between the distributions of wall temperature and heat transfer coefficient and bulk fluid enthalpy and quality. Additionally, the wall temperatures and heat transfer coefficients calculated with the well-known Dittus-Boelter correlation (Dittus and Boelter, 1930) for single-phase forced convective heat transfer are indicated by broken lines in both $T_{\mathrm{w}}$ and $\alpha$ diagrams.

Table 1 Experimental conditions.

\begin{tabular}{cccccc}
\hline Fluid & Mass flux & Pressure & Heat flux & $\begin{array}{c}\text { Inlet bulk fluid } \\
\text { enthalpy } \\
h_{\mathrm{b}, \mathrm{n}} \mathrm{kJ} / \mathrm{kg}\end{array}$ & Condition number \\
& $G \mathrm{~kg} /\left(\mathrm{m}^{2} \cdot \mathrm{s}\right)$ & $P\left(P / P_{\mathrm{c}}\right) \mathrm{MPa}$ & $q \mathrm{~kW} / \mathrm{m}^{2}$ & $255-335$ & 123 \\
\hline HCFC22 & $400-1000$ & $\begin{array}{c}4.80(0.962) \\
-4.95(0.992)\end{array}$ & $9-61$ & $266-363$ & 121 \\
\hline HFC134a & $400-1000$ & $\begin{array}{c}3.75(0.924) \\
-4.02(0.990)\end{array}$ & $8-60$ & 263 \\
\hline
\end{tabular}

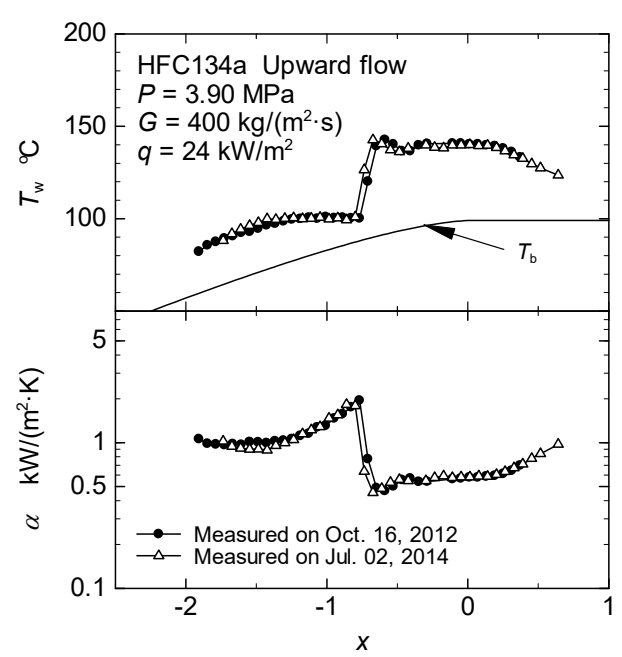

(a) Reproducibility

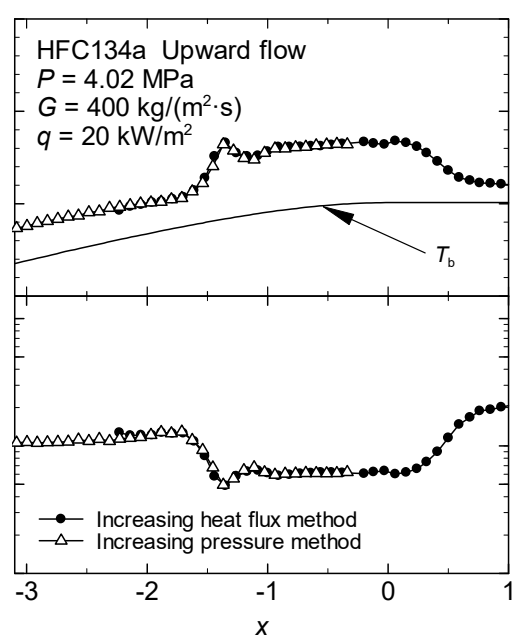

(b) Comparison of results by increasing heat flux and pressure methods

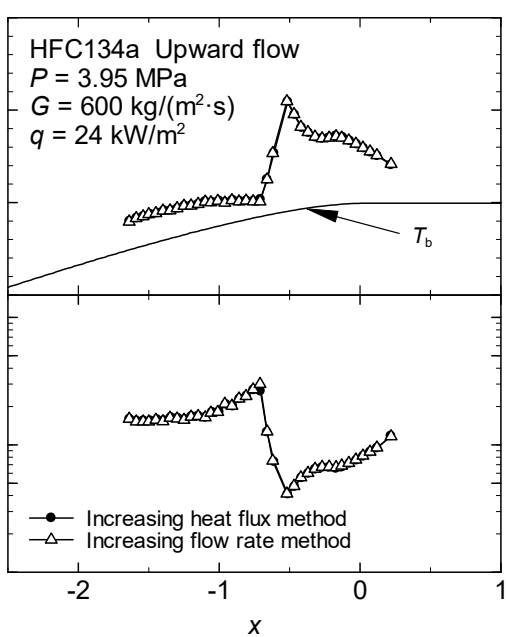

(c) Comparison of results by increasing heat flux and flow rate methods

Fig. 2 Reproducibility and effect of method difference on CHF location and post-CHF region. 


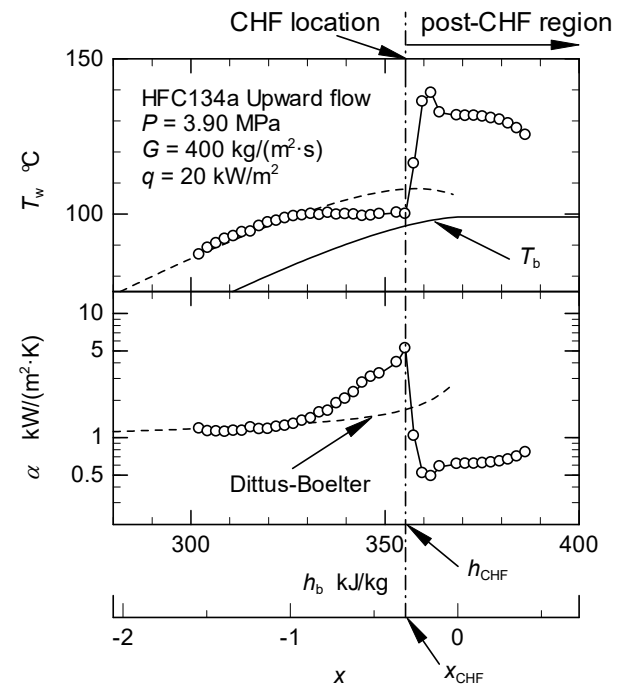

(a)

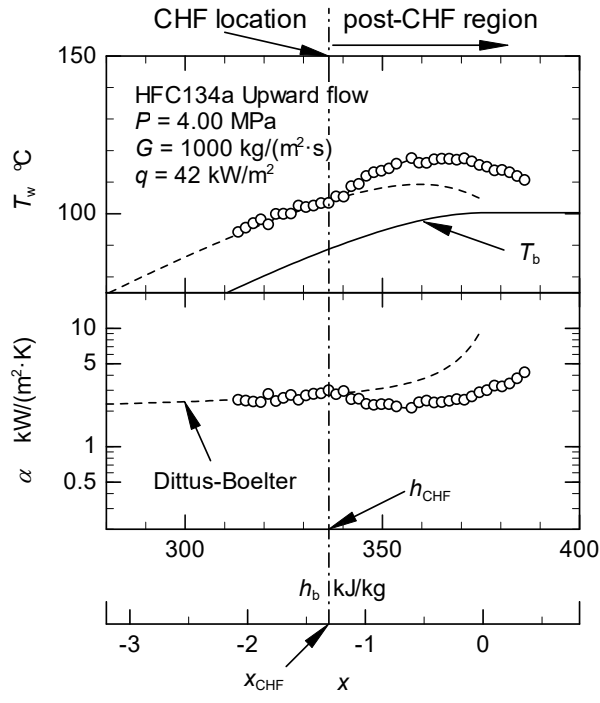

(b)

Fig. 3 CHF location and post-CHF region.

As shown in Fig. 3, in this study, the CHF phenomenon occurred mainly in the subcooled liquid region by film boiling, that is, departure from nucleate boiling (DNB), except for very low heat flux conditions where dryout occurred in the saturated region. Figure 3(a) shows a typical film boiling result, and the occurrence of CHF phenomenon is easily recognized. The sharp wall temperature rise and sudden heat transfer coefficient drop in the flow direction are significant, and the high wall temperature and low heat transfer coefficient are maintained in the downstream region. While, under some conditions as shown in Fig. 3(b), a rise in wall temperature and reduction of heat transfer coefficient became indistinct. In this study, CHF phenomenon was judged to occur when the heat transfer coefficient got worse and wall temperature rose in the flow direction from a nucleate boiling or forced convection level, irrespective of the magnitude of their changes. Such the initiating position of an increase in wall temperature and a decrease in heat transfer coefficient was defined as the occurring location of the CHF phenomenon, called the CHF location hereafter. In the figures, the CHF location is indicated by the dot-dash lines. The bulk fluid enthalpy $h_{\mathrm{b}}$ and thermal equilibrium quality $x$ at the CHF location were called as the critical enthalpy $h_{\mathrm{CHF}}$ and critical quality $x_{\mathrm{CHF}}$ here, respectively. Also, the post-CHF region was defined as the downstream region of the CHF location to the outlet of the test tube.

\section{Results and discussions}

\subsection{Characteristics of post-CHF heat transfer}

Figure 4 shows the changes of CHF location and post-CHF heat transfer for heat flux varying from 9 to $16 \mathrm{~kW} / \mathrm{m}^{2}$. At low heat flux of 9 and $10 \mathrm{~kW} / \mathrm{m}^{2}$, CHF phenomenon occurred in the saturated region and the post-CHF heat transfer characteristic can be classified as the so-called post-dryout type. At slightly higher heat flux of $12 \mathrm{~kW} / \mathrm{m}^{2}$, it was recognized that CHF mechanism seemed to become subcooled film boiling. In this manner, at relatively higher heat flux of 12 to $16 \mathrm{~kW} / \mathrm{m}^{2}$, the post-CHF heat transfer changed from the post-dryout type to the 'other' type when CHF location entered the subcooled region. Here the 'other' type of post-CHF heat transfer characteristic by film boiling greatly varied according to flow rate conditions, and were broadly classified into two distinct types: 'low flow rate type' and 'high flow rate type'. Figures 5(a) and (b) show examples of typical results of the low flow rate type and high flow rate type, respectively. Distributions of the wall temperature $T_{\mathrm{w}}$ and heat transfer coefficient $\alpha$ are plotted against the thermal equilibrium quality $x$. 


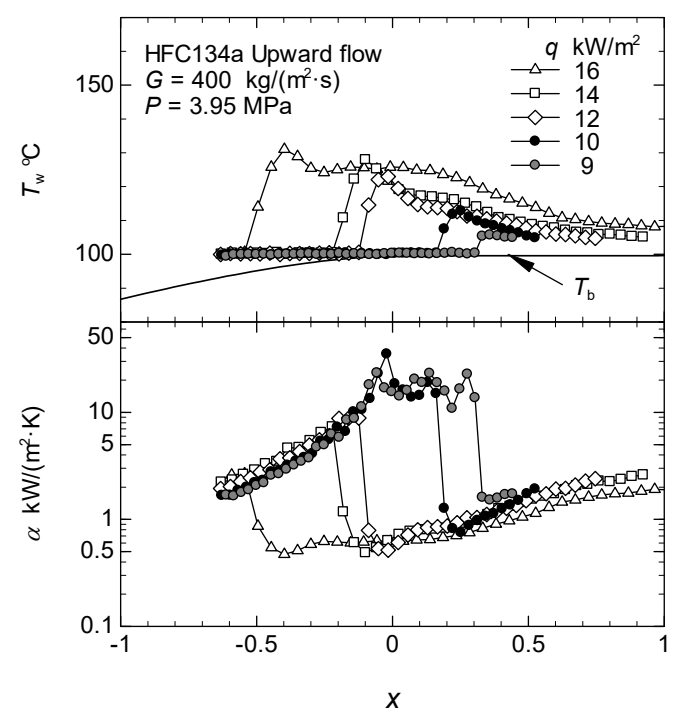

Fig. 4 Changes of CHF location and post-CHF heat transfer characteristic with heat flux increasing.

In the low flow rate type, as shown in Fig. 5(a) of low mass flux $400 \mathrm{~kg} /\left(\mathrm{m}^{2} \cdot \mathrm{s}\right)$, the heat transfer coefficient and wall temperature distributions showed irregular changes in the post-CHF region and were found to be classified into four regions in the flow direction. Four regions are separated with dot-dash lines in the figure. Such classification was similar to the results by Hammouda et al. (1996) and Nakla et al. (2011), and in the present study, in accordance with their naming, the four regions are called Regions I, II, III and IV in order of flow direction, as shown in Fig. 5(a).

After the CHF location, the heat transfer significantly got worse in Region I, and then recovered in some degree in the Region II. Hence, a sharp change in the wall temperature and heat transfer coefficient appeared at the transition from Region I to II. Subsequently, in Region III, the high temperature and low heat transfer coefficient were maintained downstream in the range from the subcooled to the saturated region. Finally, in Region IV, the heat transfer was gradually improved in the saturated region. In this study, this type of post-CHF heat transfer was dominantly observed at low flow rate, and thus named as the 'low flow rate type' of post-CHF heat transfer.

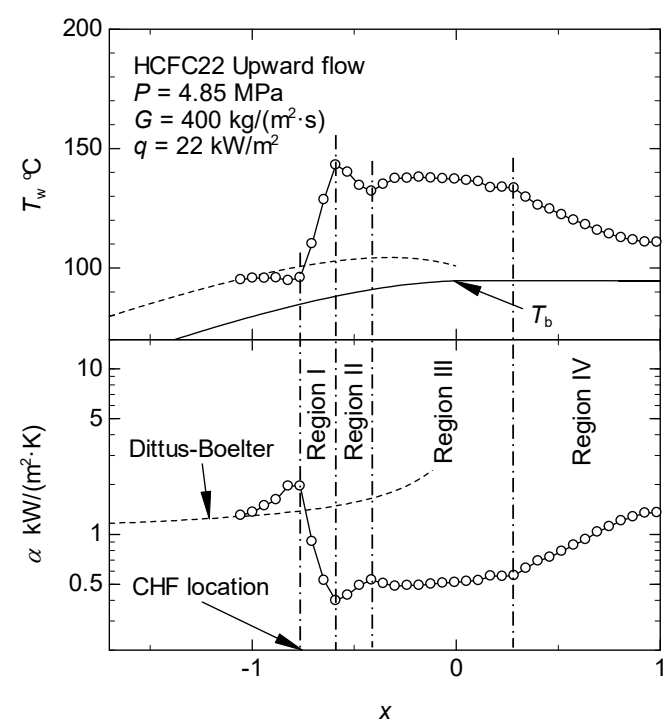

(a) Low flow rate type

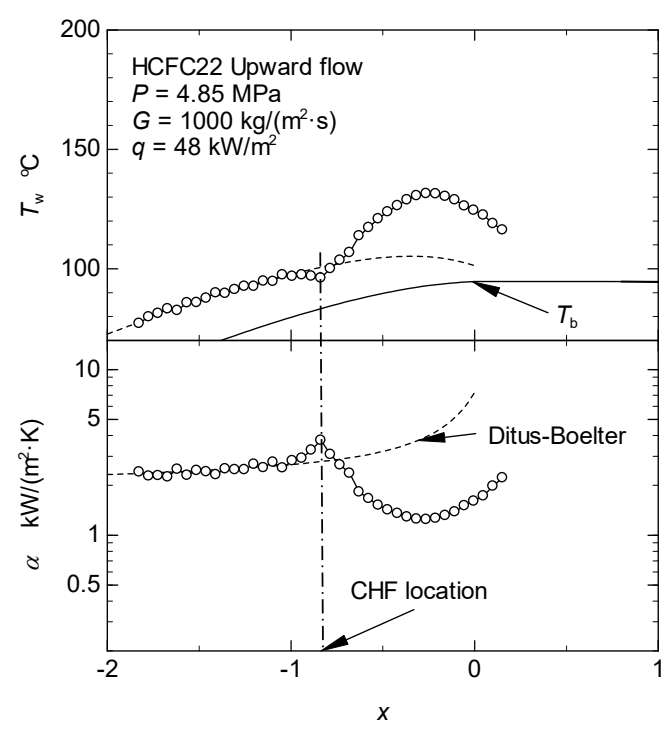

(b) High flow rate type

Fig. 5 Two distinct post-CHF heat transfer characteristics of (a) low and (b) high flow rate types. 
On the other hand, at the high flow rate of $1000 \mathrm{~kg} /\left(\mathrm{m}^{2} \cdot \mathrm{s}\right)$ shown in Fig. 5(b), the heat transfer coefficient and wall temperature after the CHF location smoothly and gradually changed in the flow direction. In this case, only two characteristic regions of the post-CHF heat transfer were recognized: the first heat transfer drop and the subsequent recovery of heat transfer. The transition between these two regions was not clear, that is, the sharp change in the low flow rate type was not observed. This type of post-CHF heat transfer was named as the 'high flow rate type' of post-CHF heat transfer. The heat transfer of the high flow rate type was generally better compared to that of the 'low flow rate type'.

The transition mass flux between the low and high flow rate types was found about $700 \mathrm{~kg} /\left(\mathrm{m}^{2} \cdot \mathrm{s}\right)$ both for HCFC22 and HFC134a, as described later.

Next, the effects of pressure, flow rate and heat flux on the characteristics of the post-CHF heat transfer in the low and high flow rate types are examined.

\subsubsection{Characteristic of low flow rate type post-CHF heat transfer}

Figures 6(a) to (c) show examples of the effects of pressure, flow rate and heat flux on the low flow rate type post-CHF heat transfer, respectively.

Although the CHF location or quality changed upstream or downstream depending on the pressure, flow rate or heat flux (Mawatari et al., 2012), the post-CHF heat transfer was not much affected by these parameters as shown in the figures. Also, the amount of quality change in each of Regions I and II was nearly not influenced. The heat transfer coefficient took the minimum at the transition between Regions I and II. In Region III, the heat transfer coefficient remained approximately constant at the level slightly higher than the minimum value at the transition. Its quality range expanded with increasing pressure or heat flux, and somewhat reduced with increasing flow rate. Region III finally disappeared at flow rate near the transition mass flux. In Region IV, the effects of pressure and heat flux were small, while the influence of mass flux was marked.

The minimum heat transfer coefficient $\alpha_{\mathrm{min}}$ at the transition between Regions I and II was plotted against the reduced pressure, flow rate and heat flux in Figs. 7(a) to (c), and found almost constant at around $0.4 \mathrm{~kW} /\left(\mathrm{m}^{2} \cdot \mathrm{K}\right)$ for HCFC22 and about $0.5 \mathrm{~kW} /\left(\mathrm{m}^{2} \cdot \mathrm{K}\right)$ for HFC134a, independently of pressure, flow rate and heat flux. The higher value of HFC134a is mainly due to larger thermal conductivity of vapor, since the differences of other properties are really small.

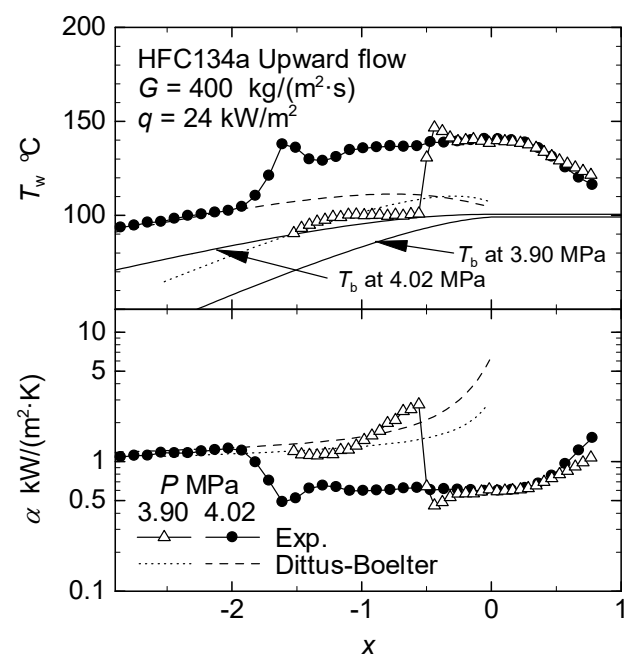

(a) Pressure effect

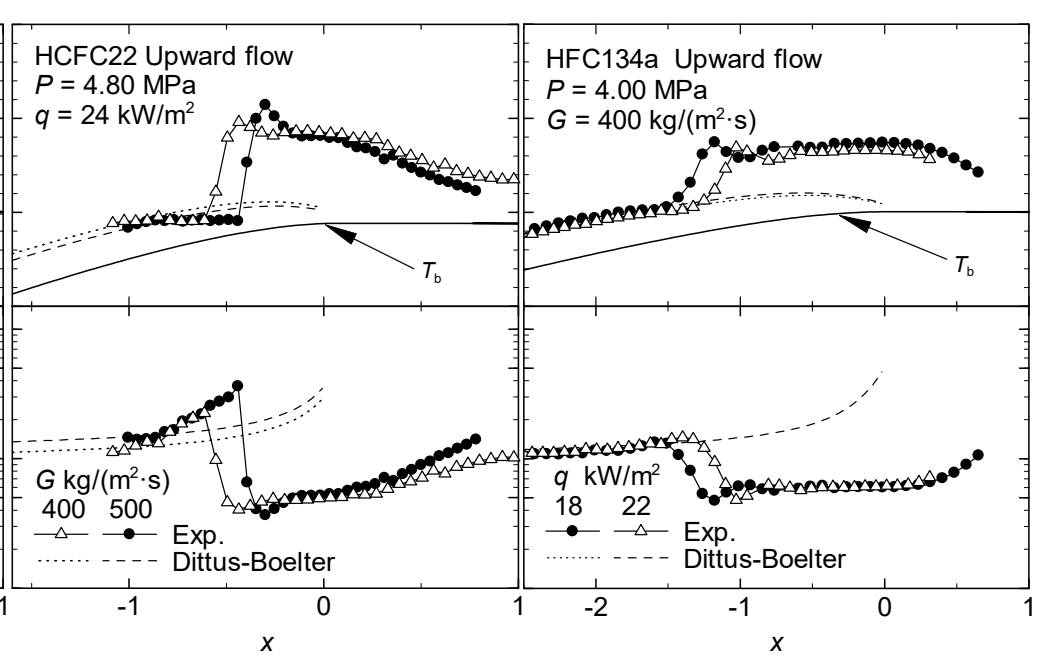

(b) Flow rate effect (c) Heat flux effect

Fig. 6 Effects of (a) pressure, (b) flow rate and (c) heat flux on low flow rate type post-CHF heat transfer. 


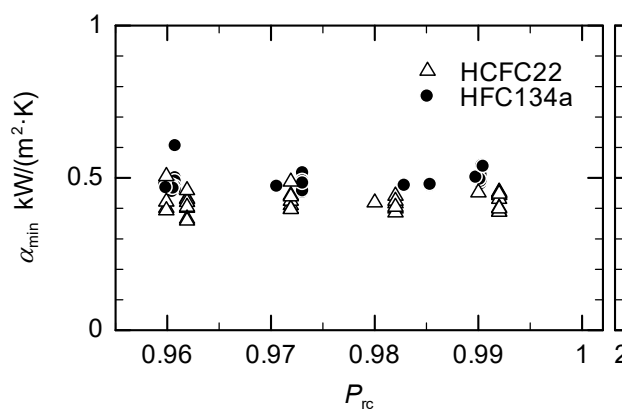

(a) Pressure effect

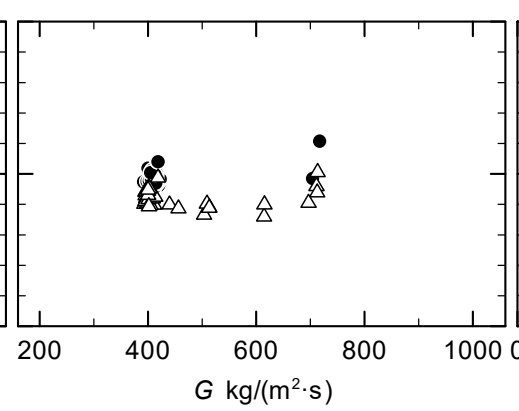

(b) Flow rate effect

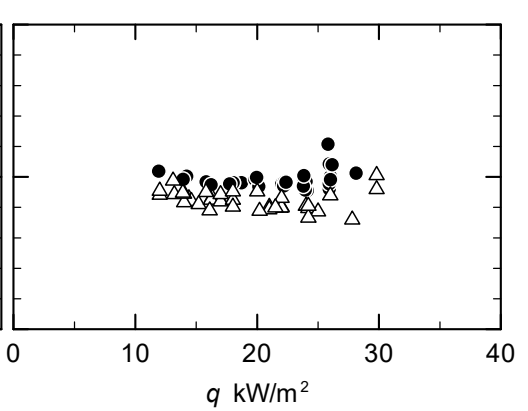

(c) Heat flux effect

Fig. 7 Effects of (a) pressure, (b) flow rate and (c) heat flux on minimum heat transfer coefficient of low flow rate type post-CHF heat transfer.

\subsubsection{Characteristic of high flow rate type post-CHF heat transfer}

Figures 8 (a) to (c) show the effects of pressure, flow rate and heat flux, respectively, on the high flow rate type post-CHF heat transfer.

In the subcooled region, the post-CHF heat transfer improved with increasing pressure or flow rate, and got worse with increasing heat flux. Pressure and heat flux effects diminished in the saturated region. A maximum of wall temperature or a minimum of heat transfer coefficient was observed at the quality slightly below 0 at low pressure or high heat flux as shown in Figs. 8(a) and (c). The reduction of the heat transfer was suppressed at higher pressure as in Fig. 8(a).

\subsubsection{Transition between low and high flow rate type post-CHF heat transfers}

The transition mass flux between the low and high flow rate types of post-CHF heat transfer was around 700 $\mathrm{kg} /\left(\mathrm{m}^{2} \cdot \mathrm{s}\right)$ both for HCFC22 and HFC134a, although it slightly increased with a decrease of pressure or an increase of heat flux. Around the transition mass flux, small changes of pressure, flow rate and heat flux revealed strong effects on the post-CHF heat transfer characteristics. Figures 9(a) to (c) show such results of the transition between the low and high flow rate type heat transfers.

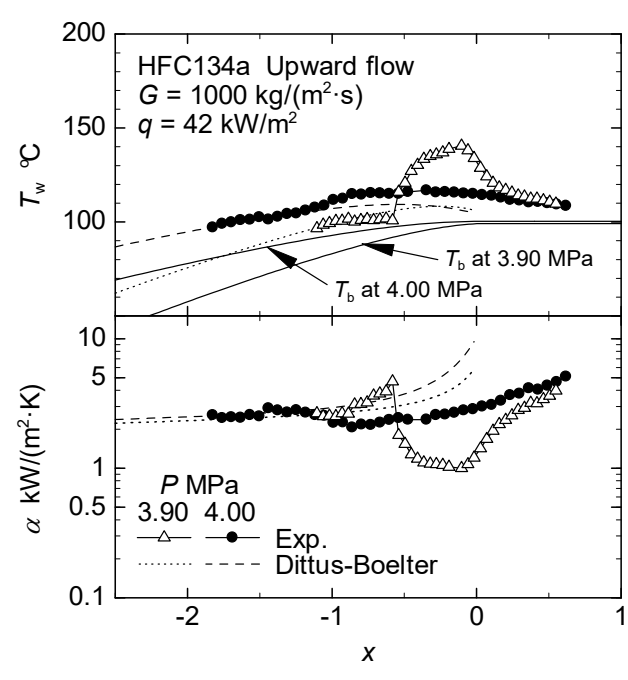

(a) Pressure effect

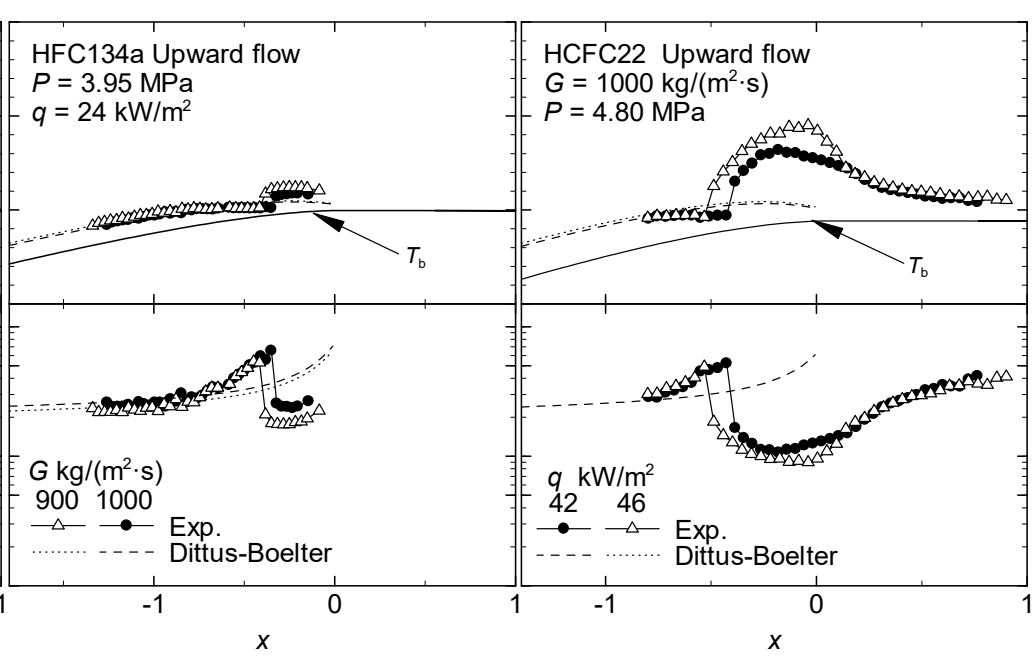

(b) Flow rate effect

(c) Heat flux effect

Fig. 8 Effects of (a) pressure, (b) flow rate and (c) heat flux on high flow rate type post-CHF heat transfer. 


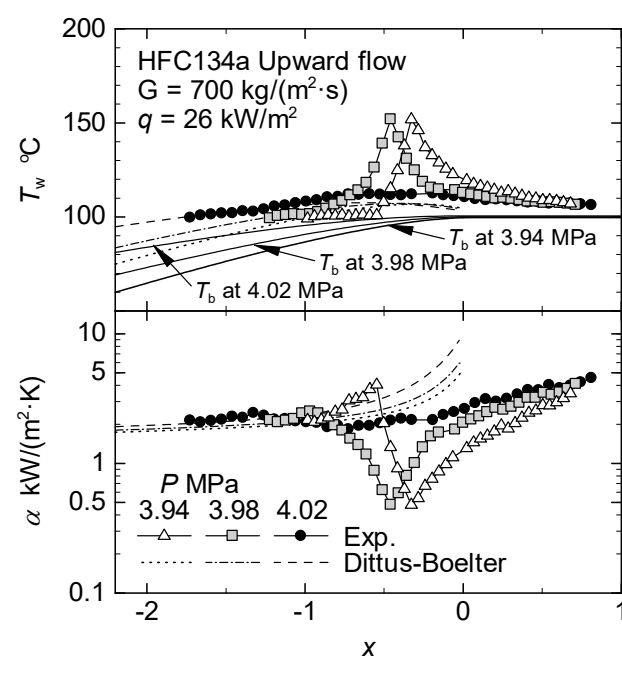

(a) Pressure effect

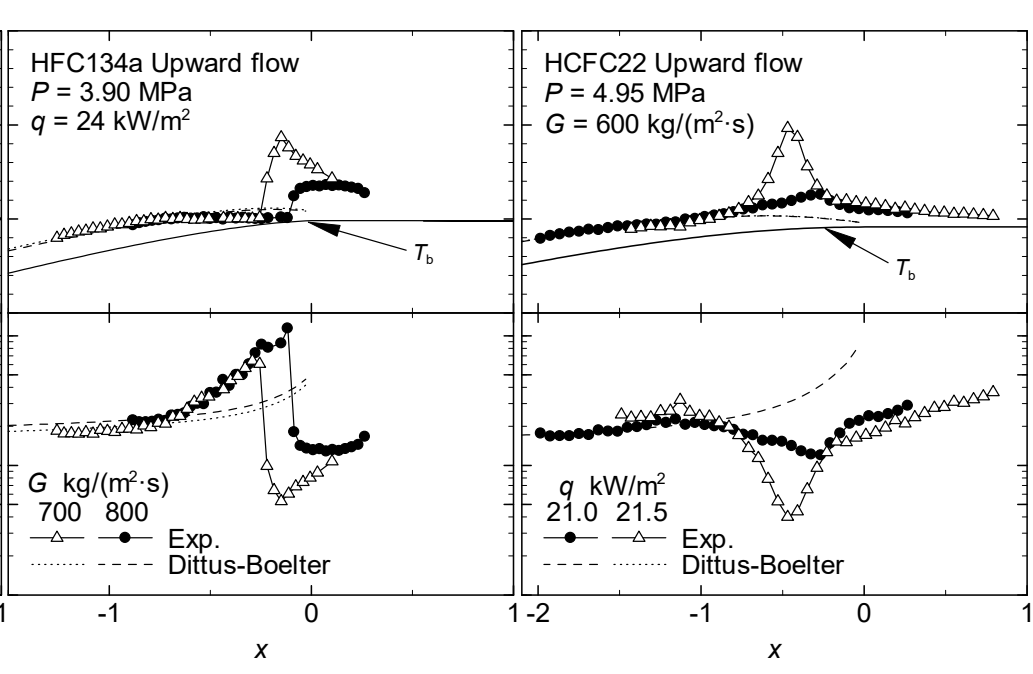

(b) Flow rate effect

(c) Heat flux effect

Fig. 9 Effects of (a) pressure, (b) flow rate and (c) heat flux on transition between low and high flow rate type post-CHF heat transfers.

As shown in Fig. 9(a), the heat transfer at the pressure below and equal to $3.98 \mathrm{MPa}$ (the reduced pressure 0.98 ) showed the low flow rate type characteristics, but the high flow rate type appeared at the slightly large pressure of 4.02 MPa (the reduced pressure 0.99). Similarly, in Fig. 9(b), the characteristics changed from the low flow rate type to the high flow rate type with a slight flow rate increase exceeding the transition mass flux. Also, in Fig. 9(c), the high flow rate type at heat flux $21.0 \mathrm{~kW} / \mathrm{m}^{2}$ shifted to the low flow rate type at a little bit high heat flux $21.5 \mathrm{~kW} / \mathrm{m}^{2}$. When heat flux was very high, the low flow rate type characteristics were observed even at the high reduced pressure over 0.99 .

\subsubsection{Regions of low and high flow rate type post-CHF heat transfers}

The regions of the low and high flow rate type post-CHF heat transfers are illustrated in Fig. 10 in the relation between the reduced pressure $P_{\mathrm{rc}}\left(=P / P_{c}\right)$ and the critical boiling number $B o_{\mathrm{CHF}}$ for different flow rate conditions. The critical boiling number $B o_{\mathrm{CHF}}$ is the boiling number for the critical heat flux $q_{\mathrm{CHF}}$ corresponding to the critical enthalpy $h_{\mathrm{CHF}}$ and critical quality $x_{\mathrm{CHF}}$ at the CHF location. The critical boiling number was also used to classify the CHF characteristics (Mawatari et al., 2012). In these figures, the discriminated post-CHF heat transfer types are plotted with different symbols: the low flow rate type shown with closed symbols, the high flow rate type shown with light gray colored symbols, and the post-dryout type shown with open symbols.

At the mass flux of $400 \mathrm{~kg} /\left(\mathrm{m}^{2} \cdot \mathrm{s}\right)$ less than the transition mass flux, the low flow rate type widely appeared, while, at the mass flux of $1000 \mathrm{~kg} /\left(\mathrm{m}^{2} \cdot \mathrm{s}\right)$ larger than the transition mass flux, the high flow rate type was extensively recognized. At $700 \mathrm{~kg} /\left(\mathrm{m}^{2} \cdot \mathrm{s}\right)$ near the transition mass flux condition, the low and high flow rate types were both observed, and the high flow rate type appeared at high pressure and expanded to high boiling number as the pressure approached the critical pressure. In the figure, the solid line roughly indicates the boundary between the two types. With a decrease of pressure or an increase of heat flux, this boundary slightly shifted to high mass flux, that is, the transition mass flux somewhat increased.

In low heat flux or critical boiling number conditions, the post-dryout type heat transfer was generally observed. The boundary line between the post-dryout type and the low or high flow rate type is denoted by the broken line.

For water data of Bähr et al. (1969) and Herkenrath et al. (1967), similar clear distinction of the characteristics of post-CHF heat transfer, the low and high flow rate types, were recognized between low and high flow rate conditions. Then, the transition mass flux was roughly estimated to be around $1000 \mathrm{~kg} /\left(\mathrm{m}^{2} \cdot \mathrm{s}\right)$ or a little more, although precise determination was difficult because of few data in the subcooled liquid region at the near-critical pressure. 


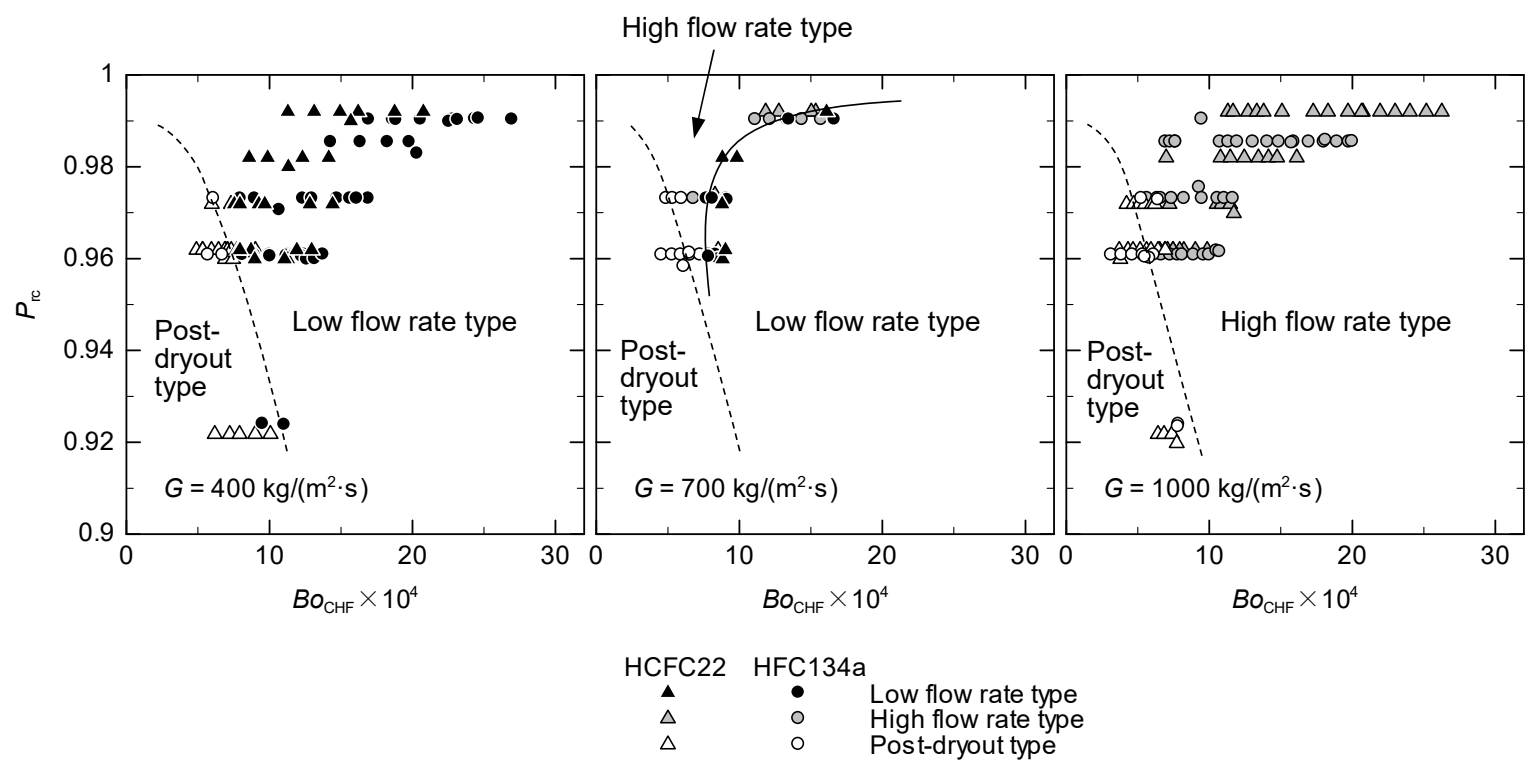

Fig. 10 Regions of low and high flow rate type post-CHF heat transfer characteristics.

\subsection{Heat transfer mechanisms in the post-CHF region}

In this section, supposed mechanisms of the post-CHF heat transfer is examined.

As has been discussed earlier, in the low flow rate type post-CHF heat transfer, there were recognized four characteristic regions, Regions I to IV. Referring to the studies on flow pattern transition and heat transfer of inverted annular film boiling by Hammouda et al. (1996) and Takenaka et al. (1989), flow pattern changes from Regions I to IV are schematically illustrated in Fig. 11.

The flow pattern in the post-CHF region after subcooled film boiling (DNB) initiation basically seems an inverted annular flow. The heat transfer mechanism in the initial region, Region I, which is characterized by abrupt reduction in the heat transfer, is supposed an inverted annular film boiling with a very smooth and stable vapor-liquid interface because the film thickness is thin enough and the vapor velocity is small. And then thermal conduction through the vapor film is mainly predominant Therefore, heat transfer coefficient decreases in the flow direction with growth of the steady vapor film.

The following region, Region II, is the transition region from Region I to Region III. In this region, because of increase of vapor velocity, the vapor-liquid interface gets wavy and the effective film thickness becomes thinner, which initiates to get heat transfer better. For this reason, sharp peaks appear in wall temperature and heat transfer coefficient distributions between Regions I and II.

In the succeeding region, Region III, the flow regime changes to agitated inverted annular flow, because liquid flows as a liquid core in the center part of the channel with a wavy liquid-vapor interface or as slug or chunk flow resulted from the liquid core breaking down. Constant heat transfer coefficient in the flow direction might be caused by the balance of evaporation and condensation and by the Leidenfrost effect.

Finally, in the saturated region from medium to high quality, Region IV, liquid is dispersed evenly and the heat transfer gets better as the quality increases due to the acceleration of vapor velocity.

In the high flow rate type, only two regions of the first decrease and following increase of heat transfer coefficient were observed, and the change across two regions was not sharp but smooth. Two regions are supposed to correspond to Regions I and IV in the low flow rate type. Under high flow rate condition, the vapor-liquid interface is difficult to be kept smooth even in Region I, and the liquid-core is easily broken and dispersed due to high turbulence by high flow velocity. Consequently, the flow of Region I directly leads up to Region IV of dispersed flow, resulting in Regions II and III not appeared. Therefore, the heat transfer coefficient generally gets better than that in the low flow rate type. 


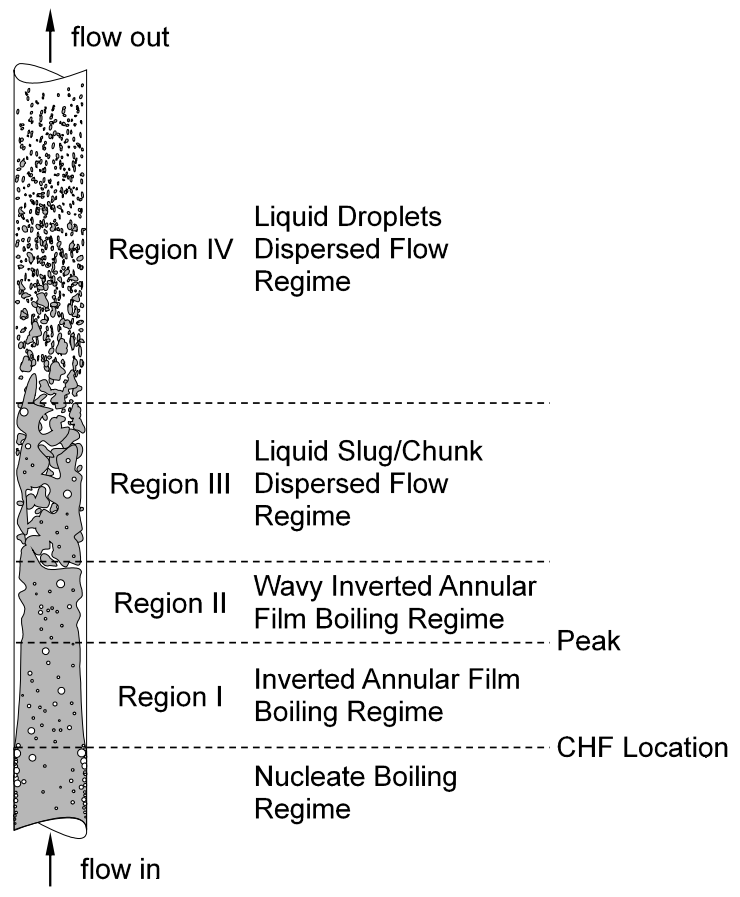

Fig. 11 Flow regimes of low flow rate type.

\subsection{Comparison with a correlation for post-CHF heat transfer}

There is no prediction method for post-CHF heat transfer at the near-critical pressure. The present measurements of heat transfer coefficient were compared with the Bishop et al. correlation (1965), as shown in Eq. (1), although the present fluid was not water, the present data were mainly obtained in the subcooled region, not in the saturated region. The pressure range of some data was out of the applicable range of Eq. (1). In the calculation, the subcooled liquid density was used for the bulk fluid density $\rho_{b}$ in the subcooled liquid region. The comparison results are shown in Figs. 12(a) and (b) for the low flow rate type and the high flow rate type, respectively.

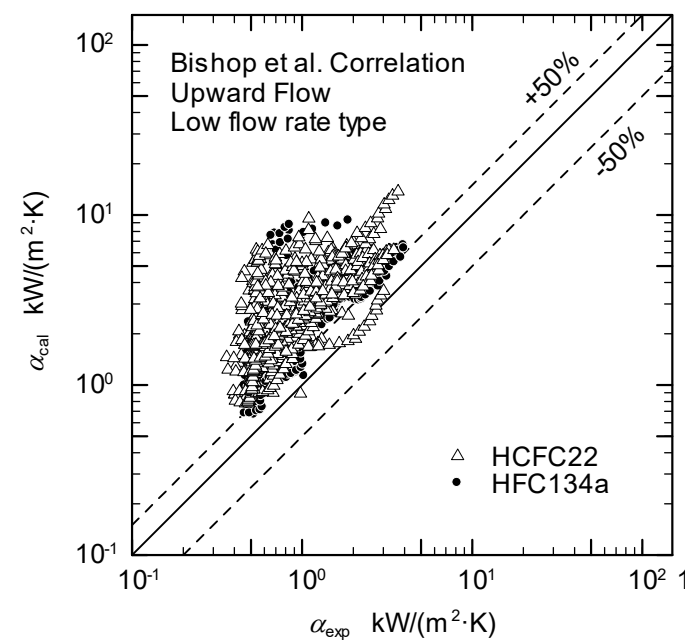

(a) Low flow rate type

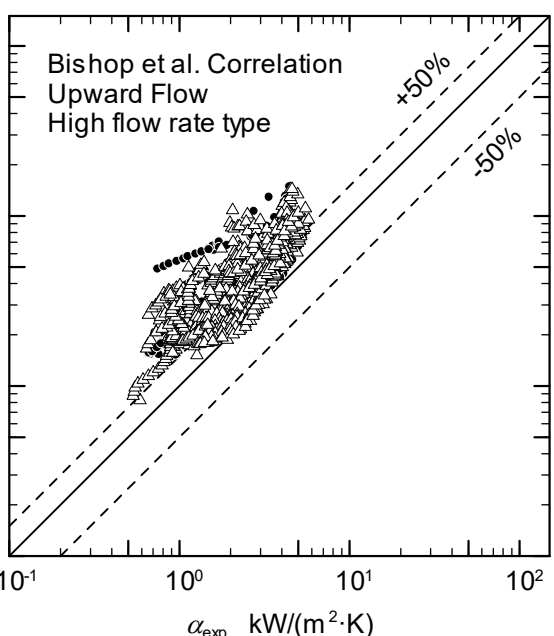

(b) High flow rate type

Fig. 12 Comparisons of predictions calculated by the Bishop et al. correlation (1965) with the present data for low and high flow rate types. 
The correlation generally over-predicted the present heat transfer coefficients with poor accuracy, particularly for the low flow rate type. The accuracy was a little better for the high flow rate type. Such disagreement means that a single correlation like the Bishop et al. correlation cannot represent the complicated variation of heat transfer. A new correlation should be developed with considering the complicated variation of heat transfer mechanism.

\section{Conclusions}

Experiments were carried out on the post-CHF heat transfer in upward flow within a tube in the near-critical pressure range of the reduced pressure from 0.924 up to 0.992, using HCFC22 and HFC134a as the test fluids. The post-CHF heat transfer attributed to subcooled film boiling was entirely obtained. Based on the obtained data, the characteristics of post-CHF heat transfer at the near-critical pressure were examined and clarified.

The post-CHF heat transfer characteristics greatly varied according to flow rate conditions, and were broadly divided into two distinct types: the 'low flow rate type' and 'high flow rate type'.

In the low flow rate type, the heat transfer showed irregular changes in the post-CHF region and was classified into four regions: Regions I, II, III and IV called in accordance with the naming of Hammouda et al. (1996) and Nakla et al. (2011). After the CHF location, the heat transfer significantly got worse in Region I, and recovered in some degree in the Region II. A sharp change in heat transfer appeared at the transition from Region I to II, and then the heat transfer coefficient took a minimum. Subsequently, in Region III, the low heat transfer coefficient was maintained downstream in the range from the subcooled to the saturated region. Finally, in Region IV, the heat transfer was gradually improved in the saturated region.

In the high flow rate type, the heat transfer after the CHF location smoothly and gradually changed in the flow direction, and only two characteristic regions of the post-CHF heat transfer were recognized: the first heat transfer drop and the subsequent recovery of heat transfer, like Regions I and IV in the low flow rate type. The heat transfer was generally better than the low flow rate type.

The effects of pressure, flow rate and heat flux on the characteristics of the post-CHF heat transfer were examined both for the low and high flow rate types.

Near the transition mass flux, the heat transfer characteristics abruptly changed between the low and high flow rate types with small changes of pressure, flow rate and heat flux. Around the transition mass flux, the high flow rate type appeared at high pressure and expanded to high heat flux as the pressure approached the critical pressure, and the transition mass flux slightly increased with a decrease of pressure or an increase of heat flux.

The post-CHF heat transfer characteristics, occurrence regions and supposed heat transfer mechanisms are summarized for the low and high flow rate types.

The existing correlation was not applicable to the post-CHF heat transfer in the subcooled region at the near-critical pressure. A new correlation should be developed with considering the complicated variations of the heat transfer mechanisms. 


\section{References}

Bähr, A., Herkenrath, H. and Mörk-Mörkenstein, P., Anomale Druckabhängigkeit der Wärmeübertragung im Zweiphasengebiet bei Annäherung an den kritischen Druck, Brennst.Wärme Kraft, Vol.21, No.12 (1969), pp.631-633 (in German).

Bishop, A. A., Sandberg, R. O. and Tong, L. S., Forced convection heat transfer at high Pressure after the Critical Heat Flux, ASME-AIChE Heat Transfer Conference and Exhibit (1965), Paper No.65-HT-31.

Chun, S. Y., Hong, S. D., Kikura, H. and Aritomi, M., Critical Heat Flux in a Heater Rod Bundle Cooled by R-134a Fluid near the Critical Pressure, J. Nucl. Sci. Technol, Vol.44 No.9 (2007), pp.1189-1198.

Dittus, F. W. and Boelter, L. M. K., Heat transfer in automobile radiators of the tubular type, University of California Publications in Engineering, Vol.2, No.13 (1930), pp.443-461.

Groeneveld, D. C., Shan, J. Q., Vasicl, A. Z, Leung, L. K. H., Durmayaz, A., Yang, J., Cheng, S.C. and Tanase, A., The 2006 CHF look-up table, Nuclear Engineering and Design, Vol.237, No.15 (2007), pp.1909-1922.

Hammouda, N., Groeneveld, D. C. and Cheng, S. C., An experimental study of subcooled film boiling of refrigerants in vertical up-flow, International journal of heat and mass transfer, Vol.39, No.18 (1996), pp.3799-3812.

Herkenrath, H., Mörk-mörkenstein, P., Jung, U. and Weckermann, F. J., Wärmeübergang an Wasser bei Erzwungener Strömung im Druckbereich von 140 bis 250 bar, EURATOM (1967), EUR-3658d (in German).

Kariya, K., Yoshizumi, K., Mori, H., Mawatari, T., Ohno, M. and Hamamoto, Y., Correlation for Critical Heat Flux at Near - Critical Pressure in Tubes, Proceedings of the 6th International Symposium on Supercritical Water-Cooled Reactors (ISSCWR6) (2013), Paper No.ISSCWR6-028.

Lemmon, E.W., Huber, M.L. and McLinden, M.O., Reference fluid thermodynamic and transport properties (REFPROP), NIST Standard Reference Database 23, Ver. 9.0 (2010), National Institute of Standards and Technology.

Mawatari, T., Yoshizumi, K., Mori, H., Kariya, K. and Ohno, M., Study on Critical Heat Flux at Near-critical Pressure, Proceedings of the 3rd International Forum on Heat Transfer (IFHT2012) (2012), Paper No.IFHT2012-195.

Mori, H., Ohno, M. and Yoshida, S., Correlations of Critical Heat Flux for Flow Boiling in Tubes at High Pressure, Trans. Jpn. Soc. Mech. Eng, Part B, Vol.65, No.639 (1999), pp.3748-3755 (in Japanese).

Nakla, M. E., Groeneveld, D. C. and Cheng, S. C., Experimental study of inverted annular film boiling in a vertical tube cooled by R-134a, International journal of Multiphase Flow, Vol.37, No.1 (2011), pp.67-75.

Oka, Y. and Koshizuka, S., Supercritical-pressure, Once-through Cycle Light Water Cooled Reactor Concept, J. Nucl. Sci. Technol, Vol.38, No.12 (2001), pp.1081-1089.

Takenaka, N., Fujii, T., Akagawa, K. and Nishida, K., Flow pattern transition and heat transfer of inverted annular flow, International journal of Multiphase Flow, Vol.15, No.5 (1989), pp.767-785.

Tong, L. S. and Tang, Y. S., Boiling heat transfer and two-phase flow (1997), Taylor \& Francis.

Vijayarangan, B. R., Jayanti, S. and Balakrishnan, A.R., Studies on Critical Heat Flux in Flow Boiling at Near Critical Pressures, Int. J. Heat and Mass Transfer, Vol.49 No.1 (2006), pp.259-268. 